This item was submitted to Loughborough's Research Repository by the author.

Items in Figshare are protected by copyright, with all rights reserved, unless otherwise indicated.

\title{
Athlete perceptions of social media benefits and challenges during major sport events
}

PLEASE CITE THE PUBLISHED VERSION

https://doi.org/10.1123/ijsc.2019-0026

\section{PUBLISHER}

Human Kinetics

VERSION

AM (Accepted Manuscript)

\section{PUBLISHER STATEMENT}

Accepted author manuscript version reprinted, by permission, from International Journal of Sport Communication, 2019, 12 (4): pp449-pp481, https://doi.org/10.1123/ijsc.2019-0026. (C) Human Kinetics, Inc.

\section{LICENCE}

CC BY-NC-ND 4.0

\section{REPOSITORY RECORD}

Hayes, Michelle, Kevin Filo, Caroline Riot, and Andrea Geurin. 2019. "Athlete Perceptions of Social Media Benefits and Challenges During Major Sport Events”. Loughborough University.

https://hdl.handle.net/2134/11897913.v1. 
1 Athlete perceptions of social media benefits and challenges during major sport events

\section{Abstract}

3 Numerous studies have focused on athlete social media use by examining the content posted

4 on social media sites, revealing an opportunity to gather firsthand experiences from athletes.

5 Utilising uses and gratifications theory as a theoretical framework to inform an open-ended

6 questionnaire, we examined athlete attitudes towards their social media use during a major

7 sport event as well as the gratifications they received and the challenges experienced from

8 this use. The study assessed a sample of 57 athletes and their social media use across 20

9 international major sport events. Findings revealed that social media allows athletes to

10 communicate with family and friends. Having a connection to home through social media can

11 make athletes feel relaxed in a high-pressure environment. The results reveal uses and

12 gratifications not previously revealed from athlete social media research, while also

13 underscoring opportunities for sport organisations to enhance social media education

14 programs provided to athletes.

15 Keywords: social media; athletes; major sport events; uses and gratifications theory;

16 prosumers. 


\section{Introduction}

Athletes have been able to enjoy enhanced interactions with fans, increase their profile and visibility, and manage their image through the power of social media (GeurinEagleman \& Burch, 2016; Hambrick, Simmons, Greenhalgh, \& Greenwell, 2010; Pegoraro, 2010). However, media and practitioners continue to scrutinize athletes' time spent on social media during major sport events, with some suggesting social media use could be impacting athlete performance and calling for social media bans during competitions (Fynes-Clinton, 2012). Others have suggested athletes replicate their daily habits as much as possible when competing at a major sport event, which may also include social media use. For example, Britain’s Olympic Deputy Chef de Mission for the 2012 Olympic Games, Sir Clive Woodward, suggested that if athletes suddenly stopped using social media during a competition there could be disruptions to their routines (Rowley, 2012).

Social media has had major impacts on athletes during major sport events. For instance, the 2012 London Olympics were deemed the Twitter Olympics due to the dominance of Twitter use by organisers as well as athletes (Jones, 2012). Fieldhouse media surveyed North American intercollegiate athletes on their social media use and revealed that $71 \%$ spent at least one hour per day on social media and $32 \%$ spent more than two hours per day. Another $31 \%$ checked their social media during a competition, while $8 \%$ stated they posted to social media during one of their competitions (Fieldhouse Media, 2018). Although there have been few investigations into Australian athletes' social media use, Australians are some of the most active users in the world. Recent statistics revealed that approximately $50 \%$ of Australians access Facebook at least once a day, with most users between the ages of 25 and 39 (Cowling, 2018).

Researchers have focused their attention on understanding how and why athletes use social media. Recent reviews of sport and social media research revealed existing literature 
1 has primarily utilised secondary data and focused on athlete tweets (Abeza, O'Reilly, Séguin,

2 \& Nzindukiyimana, 2015; Filo, Lock, \& Karg, 2015). In order to understand athletes' uses of

3 social media, uses and gratifications $(U \& G)$ theory underpinned this study. U\&G theory

4 allows researchers to examine certain populations and their use of media through the

5 perspectives of the user (Katz, Blumler, \& Gurevitch, 1973). U\&G theory is a prevalent

6 theory among social media researchers (Filo et al., 2015), however, the gratifications sought

7 by athletes is a key area requiring further investigation in order to understand why athletes engage in social media behaviours. Furthermore, advancements of $U \& G$ theory have revealed that media users are not only receiving gratifications from consuming content, but also from producing content (Lee, \& Ma, 2012; Nonnecke, Andrews, \& Preece, 2006). Although this is the case, athlete content may be restricted by the Australian Olympic Committee's (AOC) Rule 40.3. The AOC's Rule 40.3 prohibits athletes from posting about non-Olympic commercial partners, and their logos, if they are selected to compete on the Australian Olympic Team (Australian Olympic Committee, 2017). The rule may influence the content athletes post during major sport events.

Reviews of social media research (e.g., Abeza et al., 2015; Filo et al., 2015) reveal opportunities for the current study to enhance athlete social media research by examining athletes' use as a whole, rather than focusing on one specific platform, and by gathering primary data that considers athlete perspectives in order to obtain more depth on what satisfaction athletes receive from using social media, particularly during major sport events.

21 By examining Australian athletes who competed at major sport events through an open-ended questionnaire, this study sought to uncover why athletes use social media during major sport events, what satisfaction they gain from their social media use, and the perceived benefits and challenges of using social media during major sport events. The current study also advances 
1 consumers and producers.

\section{Literature Review}

\section{Uses and Gratifications Theory}

Athlete use of social media during a major sport event can be examined through the

5 theoretical lens of U\&G theory (Katz et al., 1973). U\&G theory posits that media use is goal

6 driven by the media consumer (Katz et al., 1973). Research set within U\&G theory relies on

7 the perspective of media users in order to understand their use of certain media (e.g., social media) and their reasons for using it. According to Katz et al. (1973) consumers actively seek out certain media to satisfy their individual needs and receive gratification. A key assumption of $U \& G$ theory lies in its approach to elicit data from media users. Understanding the goals of media users is commonly gained by exploring the data supplied by the users through openended questioning. Early research on $U \& G$ theory has focused on traditional media including television (e.g., Bantz, 1982; Bryant \& Zillmann, 1984) and print media (e.g., Gantz \& Trenholm, 1979). However, it is argued that the foundations of $U \& G$ theory not only allow researchers to examine traditional media, but new Internet based applications such as social media (Ruggiero, 2000).

Ruggiero (2000) suggested that U\&G theory is well suited for new media research as

it allows for the examination of key attributes unique to this form of media, including interactivity among and between consumers, multiple content types (e.g., photos, text, audio, videos), and asynchronous information. The distinguishing feature of interactivity describes the ability of users to not only consume content, but also produce content (Ha \& James, 1998). In social media, it is argued that the distinction between media consumer and producer tends to blur, which has led to the terms prosumer and prosumption being introduced (Ritzer \& Jurgenson, 2010; Quan-Haase \& Young, 2010). 
1 take more control over the distribution and production of content in new media (Ritzer \&

2 Jurgenson, 2010; Quan-Haase \& Young, 2010). Ritzer and Jurgenson (2010) suggested that

3 prosumption has increasingly become central to media behaviours of various groups as

4 consumption is no longer the only reason people seek out certain media. Research outside of

5 the sport discipline has revealed that a number of gratifications can also be elicited from

6 social media users who act as content producers in addition to being consumers (e.g., Lee \&

7 Ma, 2012; Nonnecke et al., 2006). For instance, Lee and Ma (2012) suggested that social

8 media users received gratifications in the form of information and status seeking, and

9 socialising as a result of sharing news on their platforms. Although not specific to athletes

10 and their use of social media, these investigations indicate that athletes could seek certain

11 gratifications from both consuming and producing content on their platforms (Lee \& Ma,

2012). However, it appears that many examinations of athletes and social media using U\&G theory as a framework have been conducted through a consumer lens (e.g., Browning \&

14 Sanderson, 2012; Hambrick et al., 2010) and as a result have overlooked athletes as

15 producers or prosumers (Quan-Haase \& Young, 2010).

Researchers have primarily utilised content analyses methods to examine athlete tweets to understand how athletes generate relationships and communicate with their followers through social media. For instance, professional athletes' social media content was examined and positioned within six motives: interactivity, diversion, information sharing, content, promotional, and fanship (Hambrick et al., 2010). Athletes primarily used social media to interact with fans and fellow athletes, and to post non-sports-related information (diversion). Athletes shared insights into their team, teammates, sport, training sessions, or competitive events and results of matches/competitions, while also sharing content such as videos and pictures. Athletes were less inclined to post about sports other than their own or promote upcoming sport events through their platforms (promotional). As the study focused 
1 on professional athletes and Twitter, an opportunity exists to build on this research's

2 limitations by gathering primary data from athletes about their social media use as a whole

3 and in an open-ended way, rather than placing content into categories, as many of the tweets

4 could have been placed into multiple categories (Hambrick et al., 2010).

When examining the uses and gratifications of new technology, it is also important to understand the needs that are not met (Raacke \& Bonds-Raacke, 2008). Raake and BondsRaacke (2008) referred to this as failed uses and gratifications with two key identifying features: (1) lack of motivation in using the technology, and (2) needs not being met while engaged with the media technology. Therefore, it is important to include both those who have had their gratifications met and those who have not in order to advance research underpinned by $U \& G$ theory. The current study aims to offer new insights to $U \& G$ theory by examining why athletes use social media platforms during the specific context of major sport events.

Although research has made significant contributions to our understanding of athletes' uses and gratifications for social media use, Sanderson (2013) highlighted a need for more research with athletes' perspectives on their social media use. Specifically, Sanderson (2013) suggested that athlete perspectives in U\&G theory were highly important in identifying whether athlete sentiments align with those of researchers. The gratification athletes receive when using social media was highlighted as a key area requiring further investigation. The advancements of $U \& G$ theory in new media spaces suggests that users can act as consumers and producers. As a result, a number of studies have taken the approach of examining the uses and gratifications of users as producers and consumers (Lee \& Ma, 2012; Nonnecke et al., 2006; Quan-Haase \& Young, 2010). Although this is the case, sport researchers have primarily examined athletes from a consumer perspective. This study aims to fill these gaps within U\&G theory and athlete social media research by focusing on the perspectives of athletes and their use of social media. Therefore, the first three research questions were 
1 formulated:

Research Question 1: How frequently do athletes use social media during a major sport event compared to their everyday use?

Research Question 2: Why do athletes use social media during a major sport event?

Research Question 3: What gratifications do athletes receive from using social media during a major sport event?

\section{Athletes' Use of Social Media}

Social media provides athletes with an avenue to develop relationships, particularly with fans and other athletes (Frederick, Lim, Clavio, Pedersen, \& Burch, 2012). When developing these relationships, the primary topic area of communication appears to be the personal lives of the athletes (Frederick et al., 2012) whereby insights into the daily life of an athlete are provided. Similar to sport organisations, athletes can also leverage the power of social media to endorse products, mention sponsorships deals, and publicise their personal websites (Pegoraro, 2010). Geurin (2017) examined female athlete perceptions of new media through the perspectives of athletes and found that athletes use new media to achieve four main goals: sharing their personal life with fans, developing connections with fans and followers, gaining sponsorship deals, and self-promotion, revealing social media to be an effective communication tool.

While it is apparent that there are advantages afforded to athletes who use social media, there are also a number of challenges. Social media has provided an avenue for passionate fans to express opinions, positive or negative, by sending rude public messages and/or unwanted direct (private) messages to athletes (Geurin, 2017). Cyber bullying has become commonplace for athletes, particularly those with a large online presence and who may not meet the performance expectations of fans (Sanderson \& Truax, 2014). Belittling, sarcasm, threats, and mocking represent the types of messages directed at athletes, presenting 
1 potential triggers of mental health problems for athletes (Sanderson \& Truax, 2014). Negative

2 messages may represent a key challenge for athletes during major sport events where the

3 pressure to meet performance expectations is heightened, revealing an opportunity for the

current research to explore any challenges of social media use across a sample of athletes competing in a range of major sport events.

Facebook use has also been linked to sport anxiety and concentration disruption in athletes of varying levels (Encel, Mesagno, \& Brown, 2017), which could be problematic for elite athletes around competition time particularly when a number of athletes access Facebook before a competition. Research revealed that of 298 athletes who participated in a study of Facebook use, 31.9\% accessed Facebook during a competition, and $68.1 \%$ accessed Facebook within two hours prior to their competition (Encel et al., 2017). However, Encel at al.'s (2017) study did not examine why athletes used social media during these times and how this could present challenges. Further information about social media content could help to determine the impact of social media on athletes during competitions, providing more justification for the current study to examine why athletes use social media during an event and any challenges they may encounter. As a result, a third research question is advanced:

Research Question 4: What challenges do athletes experience when using social media during a major sport event?

\section{Athlete Social Media Use During Sport Events}

For many athletes, representing their country at major sport events is a highlight of their sporting career. Social media allows athletes to document and share their experiences before, during, and after these events (Hutchins, 2011). Multiple researchers have turned their focus to understanding how athletes are engaging with social media during sport events (e.g., Hayes-Sauder \& Blaszka, 2016; Hull, 2014; Kassing \& Sanderson, 2010).

Kassing and Sanderson (2010) examined fan-athlete interaction and relationships 
1 during the Giro d'Italia, cycling's tour of Italy, by tracking athletes' posts. The study was one

2 of the earliest conducted with the primary focus of understanding the content athletes produce

3 via social media within sport event contexts. The research indicated that athletes' use of

4 social media enhanced the fans' experiences of the race through greater insights into the

5 event. Social media allowed cyclists to share commentary and their opinions on a variety of

6 issues, while fostering interactivity. Athletes also provided insights by revealing how the

7 day's ride was experienced and how they were recovering.

Twitter was also a key focus for Clavio, Walsh, and Vooris (2013), who examined how professional IndyCar Drivers used the platform during a major racing series. Results from the study revealed that drivers were mostly in control of their own accounts and posts, even during the event (Clavio et al., 2013). Content posted during racing events was sent by public relations staff. A key focus for drivers was providing both personal and professional information, facilitating direct interactions with fans, and marketing themselves as well as the racing series. These two studies provide an understanding of the ways in which athletes use social media during sport events. However, the gratifications that athletes sought by engaging in these practices require further investigation, and understanding what satisfaction athletes receive from social media could help develop a better understanding of their use of social media.

Hull (2014) examined social media content of professional golfers during a major golf tournament, and suggested that golfers primarily gave fans a glimpse into the life of a

21 professional golfer through personal stories and photos. Hull's (2014) research was also limited to one sport, however, called for research to examine other sports. The current study can build on these limitations by taking a multi-sport event approach. The content of the U.S.

24 Women's National Soccer Team was also examined during the 2015 Women's World Cup 
1 that behind the scenes insight is more interesting to followers. The strategies were consistent

2 before, during, and after the event.

The studies reviewed offer valuable insight into how athletes use social media during major sport events. However, the gratifications athletes received when engaging with fans

5 through these strategies is unclear. Content analyses have also provided a valuable

6 understanding of the types of content athletes produce. Nonetheless, the firsthand

7 perspectives of athletes appear to be a key voice missing. An opportunity exists for athlete

8 social media use during major sport events to be examined through a U\&G theory lens and

9 through the firsthand perspectives of athletes. Consistent with Sanderson's (2013)

10 recommendation for $U \& G$ theory research, the current study examines why athletes used

11 social media during major events through firsthand perspectives of athletes, what satisfaction they gain, and any challenges they face. Additionally, the current study examines athletes as both media consumers and producers, which has been previously overlooked by sport communication researchers. In making this examination, qualitative data were collected from athletes competing in major sport events.

\section{Method}

\section{Study Context}

As defined by Emery (2010), a major sport event is the "umbrella term to include mega, calendar, one-off and showcase events" (p. 160). Using this definition, a number of multi-sport and single sport events scheduled during a period of six months were identified in

21 order to gather a viable sample pool of athletes. A period of six months was selected to ensure an appropriate number of athletes relevant to the purpose of the study could participate. Past research has acknowledged the difficulties in accessing elite athletes for empirical research (e.g., Geurin, 2017). The difficulties appear to consist of finding a suitable number of athletes willing to take the time to partake in studies similar to this one (Geurin, 
1 2017). Further, a period of six months allowed for a diverse sample of athletes competing in

2 different sports competing at different times throughout the year. Major sport events included

3 in the study were selected based on the level of competition (i.e., international), timing, and

4 accessibility of athletes. Events that were international sports competitions were selected due

5 to the high-pressure environment and level of expectation placed on athletes (Hull, 2014).

6 World Championships and similar events provided an international competition component

7 as the current study was conducted during a non-Olympic year. Some events included the

8 Athletics World Championships and Artistic Gymnastics World Championships. For

9 example, the Triathlon Grand Final was the final event on the international triathlon calendar.

10 Events primarily consisted of single sport competitions with the exception of the Asian

11 Indoor Martial Arts Games (AIMAG), the Aquatic World Championships, and the New

12 Zealand (NZ) Winter Games. The events were primarily held in countries other than

13 Australia (e.g., Europe and North America).

14 Australian athletes were chosen for the study for a number of reasons. First, Filo et al.

15 (2015) highlighted a need for more research on social media consumers beyond North

16 American perspectives. Second, Australian athletes have faced harsh criticism from national

17 media for using social media during events, with some labelling their use as a competition

18 distraction (e.g., Fynes-Clinton, 2012). The criticism emphasised athletes' overuse of social

19 media during events, while suggesting athletes were more concerned with sharing their

20 experiences rather than focusing on the competition. One of Australia's gold medal

21 contenders for the 2012 London Olympics conceded her overuse of social media may have

22 been a reason for her disappointing result (Fynes-Clinton, 2012). Concerns have also been

23 raised on what content athletes see during these times. Some athletes reported being

24 distressed by negative commentary directed at them during event times (Encel et al., 2017).

25 Although these incidents are not isolated to Australian athletes, some have come forward to 
1 say their social media use could have impacted their performance. However, few athletes

2 have explained why they were using social media so frequently during these times, offering

3 an opportunity to examine the uses, gratifications, and challenges of social media.

\section{Participants}

Australian elite athletes who competed in Olympic sports (e.g., archery, athletics, skiing) at international competitions comprised the population and were recruited for the study. Further details regarding participant recruitment are provided in the procedures section. The open-ended questionnaire yielded a sample of 57 usable responses. Female $(57.90 \%)$ and male (40.35\%) respondents who ranged from 16 to 43 years old and competed across 20 events completed the questionnaire (see Table 1 for participant demographics). Ethical clearance was provided for all participants including those under 18 years of age. Social media was used by $53(92.98 \%)$ athletes, while four $(7.02 \%)$ did not use social media. These four non-users were, in turn, not included for analysis as it was outside the scope of the current study.

\section{--TABLE 1--}

\section{Materials}

In order to obtain firsthand experiences from athletes, data were collected through an open-ended online questionnaire with a focus on why athletes used social media and the gratification they received in doing so. A qualitative research design was chosen for a number of reasons. First, a qualitative research design allowed the researchers to gather more in-depth data (Tracy, 2013) from the athletes about their social media use and the gratifications they receive during events, as directed by Sanderson (2013) who highlighted that athlete perspectives were a key voice missing from athlete social media and U\&G theory literature. Second, Auerback and Silverstein (2003) indicated that qualitative research often resembles the first step in building knowledge relating to phenomena. As minimal understanding of 
1 athlete's gratifications for social media is established, a qualitative research design assisted in

2 addressing this gap and was deemed more suitable than approaching the study with a

3 quantitative design (Denzin \& Lincoln, 2011). Finally, U\&G theory posits that data should be

4 collected from media consumers (Katz et al., 1973) and producers (Ha \& James, 1998), in an

5 open-ended way.

6 The selection of an open-ended questionnaire allowed athletes to respond without any

7 interference from the research team, while the interpretive approach allowed the participants

8 to develop any conceptual outcomes (Siggelkow, 2007). Other approaches considered

9 included interviews and a close-ended survey. Interviews would have been difficult to

10 navigate with previous research revealing the difficulties in attracting a suitable number of

11 athletes to devote the time necessary to participate. For instance, Geurin (2017) invited 73

12 athletes to participate in an interview regarding their new media use, however, the final

13 sample was six interviewees. A close-ended survey would have also prohibited the depth

14 required to fully understand the gratifications and challenges associated with social media use

15 (Reja, Manfreda, Hlebec, \& Vehovar, 2003). Further, the same difficulties in attracting a

16 suitable number of athletes to complete the questionnaire would have occurred as a much

17 larger sample would have been required in order to make any inferences from the data.

18 Demographic information (e.g., age, gender, sport, and event) as well as a profile of athlete

19 time spent on social media was obtained. Qualifying questions were embedded to ensure each

20 athlete was relevant to the purpose of the current study (Gratton \& Jones, 2004). For

21 example, athletes were asked to identify the event they had most recently competed in.

A series of open-ended questions guided by U\&G theory and gaps in the literature were presented to athletes who indicated they used social media during their event. First, a

24 broad question was used to ask athletes their intentions for using social media during their event. A key gap identified in the literature was the lack of information and depth on the 
1 gratifications athletes obtain through social media use, although it is a focus of U\&G theory

2 (Katz et al., 1973). Therefore, several questions asked athletes specifically about the satisfaction obtained by using social media (e.g., what satisfaction do you intend to gain from using social media during a major sport event?). In order to derive further information on gratifications, additional questions focused on how using social media made athletes feel, how they would react if they could not use social media, and any benefits they received. The questions also sought information about any challenges encountered by athletes. Finally, athletes were asked if they would alter their social media use for future events. A copy of the questionnaire can be found in Appendix B.

\section{Procedures}

After receiving ethical clearance for the study, athletes were recruited through purposeful and convenience sampling approaches (Etikan, Musa, \& Alkassim, 2016). Following the advice of Creswell (2014), participants were selected in a purposeful approach in order to understand the research problem and question(s). A convenience sampling approach was required due, in part, to the location of the authors (Etikan et al., 2016). The sampling approach was constricted as the access of athletes presented a pragmatic constraint to the study (Suri, 2011). A government-funded high performance sport institute, relevant sport organisations, and the researchers' university sports college were contacted for assistance with recruitment. Participants were also recruited through the direct messaging function of Instagram. Athletes contacted via Instagram were identified from publicly available team lists. The lead researcher contacted the athletes with a brief message about the project and the link to the online questionnaire.

The questionnaire was developed using Qualtrics and was pilot tested within the research team as well as among several $\mathrm{PhD}$ students ranging in age, and high school students of similar age to younger athletes to ensure the wording was clear, understandable, and 
1 unambiguous (Gratton \& Jones, 2004) prior to administration. The sequencing of questions

2 was checked to ensure it was logical, and the likely completion time was also assessed. A few

3 sequencing and wording errors were identified and fixed before the final distribution. Contact

4 with athletes and the distribution of the questionnaire were conducted one week after the

5 conclusion of their event in an attempt to minimise issues of recall. Athletes completed the

6 questionnaire one to six weeks after their event. Participants took approximately 8 to 12

7 minutes to complete the questionnaire. A gift voucher prize draw was used to incentivise

8 participation. Reminder emails were sent to participants and to sport organisations after one

9 week. The questionnaire was distributed online, which provided convenience and flexibility

10 to participants who were in various overseas locations (Wimmer \& Dominick, 2003).

11 Distributing the questionnaire online also ensured the research team did not interfere with

12 athlete responses (Siggelkow, 2007).

\section{Data Analysis}

14 Descriptive and frequency analyses were used to assess demographic data. The

15 remaining data obtained through open-ended questions were analysed using thematic analysis

16 which is a "method for identifying, analyzing and reporting patterns (themes) within data"

17 (Braun \& Clarke, 2006, p.79). Thematic analysis provides a tool for sport researchers to

18 examine people's behaviours and their views on a specific issue or phenomena (Braun,

19 Clarke, \& Weate, 2016). As a result, thematic analysis has been proven as an effective

20 method in sport research (Braun et al., 2016). Thematic analysis can be used across a variety

21 of methods, while most commonly in qualitative interviewing (Braun et al., 2016). Although

22 the current study did not utilise qualitative interviewing, the analysis process was similar.

23 Data were analysed using the six phases proposed by Braun and Clarke (2006): (1)

24 familiarisation with the data, (2) generating initial codes, (3) searching for themes, (4)

25 reviewing themes, (5) defining and naming themes, and (6) producing the report. 
In order to become familiar with the data (phase 1), the first author read and re-read the responses that were downloaded from Qualtrics and entered into an Excel spreadsheet. In contrast to qualitative interviewing, the data were already written and did not need to be transcribed (Braun \& Clarke, 2006). Responses ranged from one word to 131 words in length, with a large amount of responses consisting of several sentences. While familiarising herself with the data, the first author applied U\&G theory as a guiding framework and to assist the generation of initial codes and identifying features of the data (phase 2) related to the three research questions (Braun \& Clarke, 2006). Responses to each individual question were coded first, before combining all codes in order to see the general themes emerging across the data. Similar codes were highlighted using the same colour which assisted in recognising potential themes.

Once the initial codes and potential themes were identified, they were sorted with corresponding data extracts (i.e., responses from athletes). Theme maps were used to create visual representations and assist with sorting the different codes into themes. Once the themes were finalised they were defined, before a review for any overlap was conducted (phases 35). While applying $U \& G$ theory as a framework and engaging in the phases of thematic analysis, eight key themes were identified. The themes consisted of communication with supporters, promotion, information gathering and sharing, connectedness, positive reinforcement, relaxation and escape, anxiousness, and balancing social media use. Data were coded by the first author. Therefore, in order to minimise bias and subjectivity in the analysis, the researcher approached the thematic analysis process reflexively (Morrow, 2005). Reflexivity can be carried out in a number of ways including through peer debriefing and consultation with the research team (Morrow, 2005). As a result, the first author engaged in peer debriefing with her co-authors to minimise bias and to help ensure the findings of the study were true and honest (Spall, 1998). Following the advice of 
1 qualitative researchers, peer debriefing sessions included undertaking extensive discussions

2 about the findings that were derived from the thematic analysis process (Lincoln \& Guba,

3 1985; Morrow, 2005; Spall, 1998). Morrow (2005) suggested that alternative interpretations

4 of the data can be elicited during peer debriefing sessions. Throughout the peer debriefing

5 process, a number of questions were asked about the themes and what they entail. Some of

6 the themes were renamed (e.g., positive reinforcement was originally labelled support). The results and definitions of each theme are provided in the results below (phase 6). The themes identified from the thematic analysis process are provided in Table 2 along with an operational definition and example quote.

As outlined by Braun et al. (2016), the quotations used in the subsequent results section were chosen in order to provide rich examples and illustrate the spread of the themes derived from the analysis. Numbers were assigned to protect athlete identities when displaying results. Table 3 provides a list of respondent numbers that are used throughout this results section.

\section{Results}

\section{Frequency of Social Media Use}

The following section answers the first research question which sought to understand

how frequently athletes use social media during a major sport event compared to their everyday use. Athletes revealed they access more than one of the main four platforms (i.e.,

22 Twitter, Facebook, Instagram, and Snapchat) during their event, with some accessing all four throughout the event period. Additional platforms included messaging apps such as

24 WhatsApp which were primarily used to communicate with team personnel. Surprisingly, 
1 more photo predominant platforms. Athletes appeared to have the intention of decreasing the amount of time spent on social media during events when compared with their everyday life. However, their actual usage was higher than intended. Athletes still spent less time on social media during the event than they would during their everyday use outside of major event periods (see Table 4 for how often athlete accessed social media).

\section{Social Media Uses}

The following section answers the second research question, which asked why athletes use social media to consume and produce content during a major sport event. Three social media uses were uncovered: communication with supporters, promotion, and information gathering and sharing. The themes demonstrate that athletes have become prosumers by not only using social media to consume content during an event but also to produce their own content (e.g., Lee \& Ma, 2012; Nonnecke et al., 2006).

Communication with Supporters. Communication with supporters was a primary use of social media and was defined as social media providing an avenue for athletes to keep in contact with key support networks. Athletes used social media to communicate with family, friends, fans, and their team. Respondent 42 (female, 20) provided an overview of how she communicated with her supporters and demonstrated that the various platforms had different uses by saying:

My Facebook profile is purely personal and only share content with family and friends. I use it to keep in contact with friends who are coming down to watch the tournament and also friends at home who want to keep updated with results. I mainly just use it to post photos of game times and results. Instagram is my public profile which anyone can see. During Oceania Cup, I will keep my followers updated with game results/times and whatever else I find interesting 
on tour. Snapchat is also personal and something I use with close friends only so generally not a lot of hockey or performance stuff goes on there. Athletes participated in events held in overseas locations, and for this reason social media provided an avenue for them to communicate with friends and family. Many described communicating as their primary purpose for using social media during their event.

Respondent 21 (female, 21) revealed that her communication with her support networks also involved updates on her preparation by saying "to keep my friends, family and followers who cannot attend the event updated with regular updates on how the event is going and how I am feeling going into competition." Respondent 27 (male, 20) revealed that if he could not communicate with his support networks his positive mentality may suffer:

Would have had quite an impact as I used social media to keep in contact with my girlfriend while away as well as my family and coach. Keeping in contact with them helps me mentally so I don't get too homesick and stay positive leading into the race.

Analysis also revealed two gratifications that were associated with athletes using social media to communicate with supporters: connectedness and positive reinforcement. These gratifications will be discussed further in subsequent result sections.

Promotion. The second social media use identified was promotion. The promotion theme was defined as an avenue for athletes to increase their personal profile and the profile of their sponsors during the event. The theme represents one of the reasons athletes produce content on social media, not necessarily a reason for consumption. Of the athletes that did have sponsors, not all were required to promote his or her respective sponsor(s) during the event. Respondent 5 (female, 25) revealed that she would "acknowledge them but it is up to me and there is no pressure put on me from sponsors for what I do/don't post because I'm not dealing with major money contracts." For other athletes, there was a requirement to promote 
1 sponsors, however, many athletes were not given any specifications for their social media

2 profiles and it was left up to the athlete to decide when and how to post. For instance,

3 Respondent 33 (male, 17) said, "I am required to promote, however, it is not specified to any

4 particular amount/time. I had planned to post every couple of days around the event." The pressure for promoting sponsors was suggested to increase for larger events such as an Olympic Games or Commonwealth Games, which provide a greater platform for increased exposure to a brand. Respondent 13 (male, 24) was not contractually obliged to promote his sponsors, however, he revealed he was an ambassador for an upcoming mega event and explained his unique experience:

I am not required for sponsorship reasons but I am the [international sport event] Ambassador for [my sport] for the [event]. I normally give a little bit of insight into my preparation and camp leading into the competition through social media, through Facebook and Instagram. I also do a post competition review of my performance. In any of the posts that link to my competition, in this case the AIMAG I tag the Australian Olympic Committee (as they sent the team) and most of my posts get shares through their social media platforms as well.

Athletes who were required to promote their sponsors during their event revealed the strategies they used. Respondent 21 (female, 21) summarised her strategies:

Yes [I am required to promote sponsors], by posting daily updates whilst wearing or using sponsor's product. Tagging sponsors in the photo or video and posting it on my social media channels. Using Snapchat and Instagram stories to give a bit of a behind the scenes insight on what it's like at an event of this scale.

Athletes identified that using social media during their event was also an opportunity 
1 to promote themselves by attempting to develop their personal brand. Respondent 14 (female,

2 19) provided insight on how she would promote her personal brand by saying "to promote

3 myself as an individual and an athlete in order to gain more sponsors in Australia by doing

4 interviews, uploading photos, stories."

Information Gathering and Sharing. The final use identified was information gathering and sharing. Athletes used social media to share and gather information related to their event. The theme was defined as the sharing and gathering of information related to the event such as competition times and information on competitors. Similar to the promotion theme, information sharing and gathering presents athletes in the role of both the consumer and producer. For some, social media were useful in sourcing information about current affairs outside of the event environment. Platforms such as Facebook and Twitter were primarily used for "looking at the news and other current trending issues" as described by Respondent 7 (male, 26). Other athletes sourced information about their team and fellow competitors. Respondent 13 (male, 24) summarised how he used social media to source competition related information:

Researching competitors in my division. To distract myself from the games' atmosphere. Finding the schedule for competition and monitoring for changes to schedule. Checking medal count and how other sports within the team are performing.

Respondent 22 (female, 35) shared a similar synopsis:

I see what other athletes are doing and get insight into things. What's happening, etc. Although the team uses WhatsApp for team broadcast messages and we do see each other at meal times as we stay in the same hotel.

Athletes also provided event insight to followers and found social media was a quicker way to disseminate important information that followers (e.g., fans, family and 
1 friends) wanted to know. Respondent 42 (female, 20) revealed, "I was able to do one post

2 about when the game was or how we went instead of people messaging me for information."

3 Followers were also able to see how athletes prepared for the event and receive injury

4 updates from athletes via their social media platforms. For instance, Respondent 38 (male,

5 26) revealed he used social media to provide insight into his preparation and to "inform my

6 fans about preparation or days before the event."

\section{$7 \quad$ Social Media Gratifications}

The third research question focused on what gratifications athletes receive from social media during a major sport event. Three gratifications were uncovered including connectedness, positive reinforcement, and relaxation and escape.

Connectedness. A key gratification that resulted from communicating with supporters was the feeling of connectedness. This theme was defined as athletes striving to feel connected to the outside world, support networks, and the event. Respondent 24 (female, 31) highlighted that she was able to stay connected to various people and stay up to date on news throughout her event:

Together, they mostly made me feel connected to the world, up to date on the championships - other athlete's form, teammate's results etc. Not a lot changed from normal life use of social media or the consequences of it. Athletes also highlighted that staying connected with family and friends made them feel less isolated while away from home competing at their events, particularly in their downtime, with Respondent 53 (female, 18) describing her experience: I enjoy remaining in contact with family and friends at home during our rest time away from competition or training. It allows me to feel less isolated from the social part of my life when I spent long periods away from home, making me feel connected. 
When asked about what impacts not having access to social media would have on her, Respondent 12 (female, 21) revealed the importance of staying connected to her support networks and home life in order to stay calm during major events. Respondent 12 (female, 21) said she "would feel disconnected from home and therefore stressed.” Respondent 52 (male, 20) also suggested that he would struggle to keep his support networks up to date if he was disconnected from social media by saying "[not having access to social media] would suck because then my grandmother who is my biggest supporter would have no clue how everything went." Social media allowed athletes to feel connected to the event they were competing at and develop connections with competitors. Respondent 37 (male, 17) highlighted the ability to connect so easily with other athletes was one of the key benefits of using social media by saying, "being able to talk to people at low points during and between the competitions helped keep my mental game running. Also getting to know other athletes, Facebook helped me find their names if I forgot them."

Positive Reinforcement. The positive reinforcement theme was defined as athletes receiving satisfaction through supportive messages from followers and support networks (e.g., family and friends). Social media allowed athletes to receive messages of support during their major sport event, which was suggested to increase their confidence in their performance and overall satisfaction with the event as the messages were overwhelmingly positive. Respondent 26 (female, 30) found that using social media made her realise how much support she had by saying "it makes you realise that there is a lot of support out there. So, it made me feel good about what I was doing."

The importance of receiving messages of support was also highlighted by Respondent 19 (female, 20) who explained not having access to the support messages presented via social media could potentially impact her performance during the event by saying, "it would significantly impact my overall confidence toward the event. The support given from 
1 sponsors, friends and family through social media is very mentally stabilising." Respondent

244 (male, 29) summarised how receiving 'likes' and 'comments' on his social media content

3 could provide some satisfaction:

Can make you smile when you get heaps of support/comments... My ego likes it when I get heaps of likes etc. a lot of people don't like to admit to themselves how much their ego loves getting likes, comments, virtual pats on the back. But I don't go into a tournament thinking how it's going to be an advantage. It's a small thing and sometimes a nice satisfaction.

Respondent 50 (female, 22) alluded to support in a different way and found using social media enabled her to see other athletes' experiences and made her feel better about her own emotions during the event: "made me feel better about my nerves, as seeing other athletes post about their experiences made me realise that we are all the same and are all feeling the same emotions."

Relaxation and Escape. The final theme related to social media gratifications was relaxation and escape. This theme was defined as athletes seeking an escape from their sport or the pressures associated with competing. Athletes found social media to be an escape during the event as it was beneficial or relaxing for them to take their mind off competing. Respondent 32 (male, 20) found social media as a way to relax and escape the sport pressures of the competition environment:

It only benefits me to relax myself and take my mind off my sport when I am not needed to focus on it. I don't like to always be switched on to athletics while at championships because it mentally fatigues me.

Other athletes found social media was a tool that enabled them to disconnect from the competition in their downtime, with Respondent 29 (male, 25) saying he used social media "as a distraction and to pass the time as there are often days where not much training is 
1 required and I don't like to spend too much time thinking about my event." Relaxing through using social media was also linked to having a communication channel with supporters.

3 Respondent 12 (female, 21) suggested social media was a way to enhance her performance and ensure she competes to the best of her ability: "being able to switch off during competition mode is important for me to be able to perform at my best."

The benefits of using social media as an escape from the highly competitive environment were further highlighted by Respondent 3 (female, 21), who had implemented a personal social media ban at previous events. She suggested that a social media ban could potentially lead to negative impacts on her performance rather than keeping her social media use consistent with their everyday use outside of competition times:

It made me feel much more relaxed than at other competitions where I did a social media ban and was overwhelmed with the pressures to perform and be serious and focused at training. Now, using social media I could flip that focus switch on and off whenever I wanted to...It allowed me to keep a level head, when things were getting intense in pre-comp training, I could switch that off and go back to the real world. It didn't make the pressures or stresses go away, but it did help me view them with a more level head, knowing that it's not the end of the world.

\section{Challenges of Social Media Use}

The third research question sought to uncover potential challenges associated with social media use during major sport events. Two challenges were evident: anxiousness and balancing social media use.

Anxiousness. Although social media appeared to be mostly positive for athletes, some also felt that using the platforms made them feel anxious. This theme was defined as athletes feeling uneasy through the content they were exposed to and posting on their social 
1 media pages. The ability to see information on competitors in the lead up to her event

2 provided additional stress for Respondent 4 (female, 25), who revealed "it made me feel a

3 little anxious in the lead up to competition as I didn't want to know or see other competitor's

4 results which would increase the pressure on my performances."

Deciding what to post was a cause for concern among athletes. For instance,

6 Respondent 21 (female, 21) found "being an athlete this is what I consider to be a part of my

7 job, it's a normal behaviour for me it's quite routine. I can sometimes get anxious about

8 choosing what photo to post." Respondent 51 (female, 33) found that she was feeling anxious

9 about her content on social media, particularly when she compared her content with other

10 athletes: "I would probably give more thought beforehand to how I wanted to post, so that it

11 was more regular throughout the event, and not just afterwards. I think that this would

12 alleviate some anxiety around others posting." Meanwhile, Respondent 22 (female, 35)

shared her experience with an incident involving a fellow member of the team following a photo she shared via social media. Although this incident appeared to be isolated among the sample, it demonstrates the impact that a photo could cause for an individual athlete and/or a team if not managed appropriately:

Actually - I had an incident on social media with a teammate and this really made me anxious, upset and angry. A team member asked me to remove a post because she was in it - I took this personally. She was in the background and the post wasn't related to her. The team staff got involved but they didn't even get us together to actually resolve it so [we] just avoided one another. Typical and solves nothing - the bad vibes continue. So even though I seek out positive and funny posts, there are downfalls and things out of your control. 
1 athletes with more pressure than intended. He found that if he could not access social media

2 during events he would not be able to relieve such pressures:

I actually think it will impact me in a positive way, in that I'm not really worried about the outside world but rather focusing on me and my performance. There's a little bit of pressure with social media when you post and everyone comments encouraging you on.

Balancing social media use. This theme was defined as athletes finding it difficult to balance an appropriate level of social media use. Respondent 31 (male, 23) found that there were both positives and negatives in the ways he used social media:

It did help me feel a little bit more relaxed and because there wasn't much to do or I wanted to chill out it was a good form of entertainment. However, I think it also did provide a lot of nerves, while using it most things that appear online and or people I spoke with it was about the race so couldn't mentally switch off running even though I wanted to.

Some athletes indicated that they would minimise their use for future events, while others suggested increasing the amount of content and posting would assist them to achieve their goals (e.g., attracting sponsors). Although athletes were able to use social media as an escape and as a tool to relax, some found they used social media more than they intended to, with some also saying they could find better alternatives for future events. Respondent 50 (female, 22) stated, "I could use my time better i.e. by doing something a bit more productive where I can still switch off, do more mindfulness." Other athletes found that they would also minimise their use in order to stay focused on themselves and not others during the competition. Respondent 23 (male, 20) found he was able to maintain a good balance through a social media plan:

Specific timing for social media, time limits on it and making sure to stay 
focused on what I wanted to do on social media, things like not using it before bed, or when I first wake up, not using it 4 hours out from my race and 1 hour after my race, not using it during practice or in meetings to ensure I stayed focused on what I needed to.

The positives and negatives of social media use were also relayed by Respondent 37

(male, 17) who found if he couldn't access social media as often then meeting other athletes competing at the event would be difficult. Conversely, he suggested having minimal access

would have made him more focused on competing, recovery, and his own teammates:

It would make meeting new people and making friends with other athletes harder because you might not have the opportunity to introduce yourself in person. It would also make it harder to promote yourself or share photos and tell friends about the experiences you're having. On the other side, it might make me as an athlete focus more on the competition e.g. I may have used recovery times more effectively or been more involved with teammates and the training we did beforehand.

\section{Discussion and Conclusion}

The purpose of this study was to examine why athletes use social media during a major sport event as well as the gratifications they receive and the challenges they experience from this use. The current study has contributed to athlete social media research and U\&G theory by addressing three research questions. Each of the three research questions examined athlete's use of social media as a whole, rather than focusing on one particular platform. Although some athletes reported using particular platforms for particular things at times, the results overall reflect the gratifications and challenges associated with a range of platforms. The approach builds on previous research that has focused on individual platforms, such as Twitter (e.g., Hambrick et al., 2010; Kassing \& Sanderson, 2010). The first question asked 
1 "why do athletes consume and produce social media content during a major sport event?" and

2 revealed three uses, including: communication with supporters, promotion, and information

3 gathering and sharing. The themes align with previous research (e.g., Geurin, 2017;

4 Hambrick et al., 2010; Pegoraro, 2010), while also offering new insights into athlete social

5 media use during events.

6 Communication with supporters resonates with Hambrick et al.'s (2010) diversion

7 category which revealed professional athletes shared stories of family and friends. However,

8 in the current study athletes did not reveal they were sharing stories, instead they were

9 communicating personal matters with family and friends who were unable to attend the event.

10 The theme represents an important finding that was elicited through firsthand perspectives

11 lacking from U\&G theory literature (Sanderson, 2013) as private communication would not typically be available for content analyses studies. Further, athletes did not mention they were directly responding to fans through replies on comments (Clavio et al., 2013; Hull, 2014).

14 Communicating with family and friends was linked to a number of gratifications including connectedness, positive reinforcement, and relaxation and escape, which was also suggested to have positive impacts on their athletic performance.

Insights into the events were also provided to followers or supporters of the athlete, extending previous professional athlete research (Hambrick et al., 2010) and aligning with event specific research that suggested athletes shared commentary on the events (Clavio et al., 2013; Hayes-Sauder \& Blaszka, 2016; Hull, 2014; Kassing \& Sanderson, 2010). In addition, athletes in the current study were able to present their followers with images of the competition venue/city revealing similarities to previous research (Hayes-Sauder \& Blaszka, 2016; Hull, 2014), while also sharing their thoughts on their preparation and performances

24 during the event. Social media also provided another avenue for athletes to gather information. In the current study, the information gathered was specific to the event, with 
1 athletes receiving information from their team management and event organisers,

2 demonstrating that various sport stakeholders have adopted social media as a primary

3 communication platform.

The promotion and information gathering and sharing themes align with uses

5 previously identified in professional athlete social media research (Hambrick et al., 2010;

6 Pegoraro, 2010), revealing similarities in how athletes adopt social media in their everyday

7 lives and during major sport events. Athletes promoted personal sponsors and engaged in

8 self-promotion, aligning with previous research in the context of sport events (Clavio et al.,

9 2013; Hull, 2014). Athletes also used social media to market themselves to sponsors and

10 manage their own brand supporting previous work on athlete branding (Clavio et al., 2013;

11 Geurin, 2017; Pegoraro, 2010). Some athletes preferred to manage their brand by posting

12 about their achievements at the competition, suggesting that major sport events provide a

13 unique opportunity for athletes to enhance their brand.

14 Athletes who use social media as a form of promotion may be impacted by the

15 Australian Olympic Committee's Rule 40.3. As outlined previously, the rule focuses on how

16 an athlete's name and image is used in marketing, sponsorship, and other promotional

17 activities for those selected on the Australian Olympic Team. The AOC suggested athletes

18 may post content about their personal experiences, share AOC digital content, and obtain

19 permission of teammates or competitors if they post a photo containing them. However,

20 athletes are prohibited from posting any content related to their personal sponsors who are not

21 Olympic commercial partners. As the rule only applies during an Olympic Games, the

22 impacts on the athletes who participated in the current study are minimal (Australian

23 Olympic Committee, 2017). Yet, this may cause issues for some athletes who suggested they

24 have more pressure to promote their sponsors during larger events and continue to represent

25 Australia during an Olympic Games. 
The promotion and information gathering and sharing themes demonstrated athletes undertaking the role of content producers. Specifically, the information sharing theme aligned with research in other disciplines that examined social media users' role as content producers (e.g., Lee \& Ma, 2012). Meanwhile, the promotion theme may be unique to athletes in their pursuit of sponsorships in order to generate an income or awareness of their sport (Clavio et al., 2013; Parmentier \& Fischer, 2012).

The second research question asked "what gratifications do athletes receive from using social media during a major sport event?" Athletes obtained several types of gratifications from using social media which were represented in three themes:

connectedness, positive reinforcement, and relaxation and escape. These findings provided a deeper understanding of the gratification athletes receive when using social media derived from athlete perspectives (Sanderson, 2013). Athletes felt connected to their support networks and to the outside world through their social media use, suggesting this alleviated some feelings of nervousness. Further, the positive reinforcement gratification was also received from family, friends, and followers sending athletes messages of encouragement. The positive reinforcement theme builds on previous work that found athletes receive positive messages of support in competition contexts (Sanderson \& Truax, 2014). Notably, athletes in the current study did not disclose any negative messages they received. Therefore, the way support was manifested in the current study was dissimilar to Sanderson and Truax's (2014) study that revealed support was directed to athletes in response to an influx of negative messages.

Both connectedness and positive reinforcement could contribute to better performances as athletes linked these gratifications to feeling better about their performances on multiple occasions. Strong connections to social support networks have been associated with better performances in literature outside of the social media realm (Freeman, Rees, \& 
1 Hardy, 2009). The finding reveals that social media may provide another avenue for athletes

2 to receive social support. The remaining gratification theme was relaxation and escaping the

3 pressures of the sport environment. Athletes appeared to seek this gratification during their

4 down time. The theme does not align with previous research on athlete social media use

5 underpinned by U\&G theory.

6 The third research question asked "what challenges do athletes experience when using

7 social media during a major sport event?" Although a large body of research has focused on

8 the positive aspects of social media use, this study found that athletes faced two key

9 challenges: anxiousness and balancing social media use. The two themes reveal additional

10 challenges to those already identified, such as online bullying based on athletes not meeting

11 performance expectations (Sanderson \& Truax, 2014). Athletes revealed that anxiousness stemmed from deciding what to post and comparing themselves to other athletes. Athletes also felt a sense of anxiety through seeing competitors' posts. However, previous work revealed that Facebook caused a disruption of concentration for some athletes leading into a competition and stimulated sport anxiety (Encel et al., 2017).

Finally, athletes indicated balancing the appropriate amount of social media use was challenging. For instance, some of the experiences at the events examined resulted in some athletes opting to minimise their use and seek alternatives that may be more efficient to escape pressures. Others suggested they would increase their social media use for future events, with a focus on interactivity aligning with previous research suggesting a primary reason for athletes using social media is to interact with followers and promotional purposes

22 (Clavio et al., 2013; Hull, 2014; Kassing \& Sanderson, 2010).

The findings reveal areas where uses, gratifications, and challenges interrelate.

24 Communication with supporters was associated with all three gratifications revealed.

25 Specifically, communication with supporters made athletes feel connected, a sense of positive 
1 reinforcement, and relaxed during events. Information sharing and gathering was also linked

2 to connectedness and relaxation and escape. For instance, athletes used social media to gather

3 information about current affairs or news, which made them feel connected to what was

4 happening at home, while providing a diversion to competition pressures.

The challenges also connect with the reasons athletes used social media. Athletes

6 reported feelings of anxiousness upon viewing their competitor's content. However, some

7 athletes used social media specifically to gather information on their competitors. The

8 findings reveal that although athletes may be interested in their competitor's content, it may

9 present feelings of anxiousness if they begin to make comparisons. In terms of balancing

10 social media use, some athletes suggested they would put more effort into promotional

11 content at future events.

\section{Theoretical Implications}

The findings from this study have contributed in two ways. First, the study offered new information for athlete social media research and $U \& G$ theory by providing a deeper understanding of the gratifications received from social media use. Although social media use appeared to be viewed as primarily positive, the study was also one of the first to examine the challenges associated with social media use through the lens of $U \& G$ theory. Few studies have examined the challenges athletes face and whether these can impact their use of social media in the future through $U \& G$ theory. Instead, examinations have focused attention on the reasons athletes use social media (e.g., Hambrick et al., 2010). Although these studies have made valuable contributions to $U \& G$ theory and athlete social media literature, the challenges identified in this study could represent the reasons why athletes may decide not to use social media during future events. Athletes in the current study suggested they may alter or minimise their social media use in the future. 
1 that became evident align with previous research. Raake and Bonds-Raake (2008) examined

2 the failed gratifications of Facebook users. The authors found that failed gratifications were

3 evident for a number of reasons including feelings of intimidation, which was caused by the

4 content they viewed. Similarly, the current study builds upon Raake and Bonds-Raake's

5 (2008) study by revealing athletes experienced feelings of anxiousness for a number of

6 reasons including seeing their competitor's content. The finding suggests that athletes may

7 not only decide to minimise their social media use based on negative feelings, but also that

8 other social media users may experience similar emotions. Further, Raake and Bonds-Raake

9 (2008) reported non-users opted out of using social media as they were too busy. The finding

10 has applications to athletes, as the current study revealed some would alter their use for future

11 events in an effort to focus more on themselves and their performance at the event.

Second, Sanderson (2013) highlighted that much of the work integrating U\&G theory

and athlete social media has primarily focused on the consumption side, while work has

begun to explore the production avenue. Thus, the current study contributes to U\&G theory

and athlete social media research efforts through an examination of both the content consumer and producer perspectives which has received attention in other disciplines (e.g.,

17 Lee \& Ma, 2012; Quan-Haase \& Young, 2010). Specifically, the study offers a new variable in the form of promotion that may be unique to athletes taking the content producer approach in their pursuit of sponsorship.

\section{Managerial Implications}

The findings of the current study have implications for practitioners. First, the Time

22 Well Spent movement, which aims to minimise the impact technology has on society and individuals, highlighted that social media can increase stress and anxiety amongst users

24 (Centre for Humane Technology, n.d), with the current study revealing athletes may 
1 media addiction and lack of mindfulness can lead to emotional exhaustion (Sriwilai \&

2 Charoensukmongkol, 2016). Therefore, sport organisations may seek to promote techniques

3 that can enhance athlete wellbeing and minimise stress and anxiety such as mindfulness

4 training. Mindfulness training has been suggested to reduce stress in some athletes and

5 potentially bolster their performances and may assist athletes in finding balance with their

6 social media use (Birrer, Röthlin, \& Morgan, 2012; Goodman, Kashdan, Mallard, \&

7 Schumann, 2014).

Second, the findings also reveal the need for sport organisations to educate athletes in ways that may help them manage challenges and negative feelings related to social media use

10 if athletes need to continue using social media to promote sponsors or connect with family

11 during events (Sanderson, Browning, \& Schmittel, 2015). Again, current education resources that promote appropriate use could be improved by acknowledging the challenges athletes face with social media (Sanderson et al., 2015). Sport organisations may benefit by providing athletes with strategies on how to filter competitors' posts so they are not visible in the athlete's social media feeds, as this was a source of anxiety for some athletes. Education resources could also include developing social media plans to minimise the challenges faced by athletes. The plan may include athletes choosing to unfollow competitors' feeds before competitions to minimise content showing event-related information and reduce the potential to cause anxiousness. By improving practice, the reputation of sport organisations could be

20 improved, as the amount of issues related to athlete social media use may decrease, while

21 criticism of organisational practices related to performance may be alleviated.

\section{Limitations}

While the current study offered new insight into athletes' uses and gratifications for social media use during major sport events, there were a number of limitations. As social media use among athletes (and in general) has recently received a lot of media criticism, 
1 while sport organisations have threatened to ban the platforms during competitions in the

2 past, participants may have demonstrated social desirability bias when recording their

3 answers to the questionnaire (Grimm, 2010). Participants may have wanted to demonstrate

4 that social media is more of a positive resource rather than harmful in an effort to overcome

5 the negative connotations that currently exist, as well as to portray healthier behaviors.

6 Limitations also exist in the sampling procedure. As the authors of the study were

7 based in Australia, a convenience and purposeful sampling approach was used to obtain

8 access to Australian athletes. By using this approach, the findings of the study are not

9 generalizable and may not be applicable to all athletes and their experiences with using social

10 media during major sport events (Etikan et al., 2016). Although not an ideal approach, the

11 pragmatic constraints of accessing athletes prohibited the authors from using other sampling procedures (Suri, 2011). Accessibility was also limited following the conclusion of the major event. Therefore, respondents were asked to recall how they used social media during their selected event. This is a common problem for research that utilises the questionnaire method with respondents often unable to recount the required information (Wimmer \& Dominick, 2003). In order to address this limitation, we contacted the majority of athletes within a week after their competition and although this was the case, not all participants completed the open-ended questionnaire within this time frame. Questionnaires were completed between one and six weeks after events. Therefore, recall may be affected due to the time lapse since

20 the event occurred.

\section{Future Research}

A number of areas for future research arise from the findings and limitations. First, as the study only revealed four athletes who did not use social media during their event, future

24 research could seek to further explore reasons for other athletes choosing to disengage from social media in the preparation and event phases, and the potential positive or negative 
1 impacts this may have on them personally and professionally. U\&G theory provides an

2 appropriate lens to examine this phenomenon as it allows researchers to investigate failed

3 gratifications (Raacke \& Bonds-Raacke, 2008). This research would benefit from the

4 perspectives of athletes through interviews. Interviews would enable more in-depth

5 information to be collected, whereas athletes may only provide some brief responses to open-

6 ended questionnaires as experienced with this study. Further, a number of additional

7 questions could be explored using U\&G theory that were beyond the scope of the current

8 study. For instance, researchers could examine the differences between the gratifications

9 sought versus those that were obtained when using social media. As the current study

10 revealed athletes use social media for both private and public communication, an examination

11 could investigate any differences between the gratifications or challenges associated with

12 both of the areas. Researchers should also continue to explore whether athletes have

13 strategies while using social media. For instance, athletes in the current study reported

14 different uses for different platforms.

Second, the open-ended questionnaire primarily focused on the positive aspects of social media use for athletes in order to gauge any satisfaction athletes received. It was revealed that athletes appeared to enjoy receiving positive messages from followers, however, there was minimal mention of negative messages. Future research could seek to examine any negative messages athletes may receive and how this could impact them

20 personally or professionally during events. Researchers may seek a mixed methods approach

21 involving interviewing or surveying athletes about these messages in order to gain in-depth data and analysing message content. These methods will allow researchers to delve deeper into how messages are managed by athletes or where athletes may seek external support (e.g., coach, sport psychologist, family) in order to minimise any negative impact during competition. 
1 Lastly, future research could also gather the perspectives of athlete support networks

2 such as family and friends. A study could include questioning whether family and friends

3 interact with athletes in similar ways during non-event and event times, or attempt to provide

4 more support during competition times, why this would be the case, and how this is achieved.

5 A qualitative research design including interviews or an open-ended questionnaire could be

6 employed. Gaining these additional perspectives would also help address the limitations of 7 this study. 


\section{References}

Abeza, G., O’Reilly, N., Séguin, B., \& Nzindukiyimana, O. (2015). Social media scholarship in sport management research: A critical review. Journal of Sport Management, 29(6), 601-618. https://doi.org/10.1123/JSM.2014-0296

Auerback, C.F., \& Silverstein, L.B. (2003). Qualitative data. New York: NYU Press.

Australian Olympic Committee. (2017, May). AOC Rule 40.3. Australian Athletes Guide. Australian Olympic Committee. Retrieved from http://olympics.com.au/files/dmfile IAOC17_0127_Rule40_V2.pdf

Bantz, C. R. (1982). Exploring uses and gratifications: A comparison of reported uses of television and reported uses of favorite program type. Communication Research, 9(3), 352-379. https://doi.org/10.1177/009365082009003002

Birrer, D., Röthlin, P., \& Morgan, G. (2012). Mindfulness to enhance athletic performance: Theoretical considerations and possible impact mechanisms. Mindfulness, 3(3), 235246. https://doi-org.libraryproxy.griffith.edu.au/10.1007/s12671-012-0109-2

Braun, V., \& Clarke, V. (2006). Using thematic analysis in psychology. Qualitative research in psychology, 3(2), 77-101. https://doi.org/10.1191/1478088706qp063oa

Braun, V., Clarke, V., \& Weate, P. (2016). Using thematic analysis in sport and exercise research. In B. Smith \& A. Sparkes (Eds), Routledge handbook of qualitative research in sport and exercise, 191-205. London: UK.

Browning, B., \& Sanderson, J. (2012). The positives and negatives of Twitter: Exploring how student-athletes use Twitter and respond to critical tweets. International Journal of Sport Communication, 5(4), 503-521. https://doi.org/10.1123/ijsc.5.4.503

Bryant, J., \& Zillmann, D. (1984). Using television to alleviate boredom and stress: Selective exposure as a function of induced excitational states. Journal of Broadcasting \& Electronic Media, 28(1), 1-20. https://doi.org/10.1080/08838158409386511 
1 Centre for Humane Technology. (n.d). The problem. Centre for Humane Technology. Retrieved from http://humanetech.com/problem/

3 Clavio, G., Walsh, P., \& Vooris, R. (2013). The utilization of Twitter by drivers in a major racing series. International Journal of Motorsport Management, 2(1), 2.

5 Cowling, D. (2018, September 01). Social Media Statistics Australia - August 2018.

6 7 SocialMediaNews.com.au. Retrieved from https://www.socialmedianews.com.au/ $\underline{\text { social-media-statistics-australia-august-2018/ }}$

Creswell, J.W. (2014). Research design: Qualitative, quantitative, and mixed methods approaches (4th ed.) Thousand Oaks, CA: SAGE

Denzin, N. K., \& Lincoln, Y. S. (Eds.). (2011). The SAGE handbook of qualitative research. Thousand Oaks, California: Sage.

Emery, P. (2010). Past, present, future major sport event management practice: The practitioner perspective. Sport Management Review, 13(2), 158-170. https://doi.org/10.1016/j.smr.2009.06.003

Encel, K., Mesagno, C., \& Brown, H. (2017). Facebook use and its relationship with sport anxiety. Journal of Sports Sciences, 35(8), 756-761. http://doi.org/10.1080 $\underline{102640414.2016 .1186817}$

Etikan, I., Musa, S. A., \& Alkassim, R. S. (2016). Comparison of convenience sampling and purposive sampling. American Journal of Theoretical and Applied Statistics, 5(1), 14. https://doi.org/10.11648/j.ajtas.20160501.11

Fieldhouse Media. (2018, June 12). 2018 Survey Results: Social Media use of College Student Athletes. Fieldhouse Media. Retrieved from http://www.fieldhousemedia.net $\underline{\text { tag/social-media-athletes/ }}$

Filo, K., Lock, D., \& Karg, A. (2015). Sport and social media research: A review. Sport Management Review, 18(2), 166-181. https://doi.org/10.1016/j.smr.2014.11.001 
1 Frederick, E., Lim, C. H., Clavio, G., Pedersen, P. M., \& Burch, L. (2012). Choosing between the one-way or two-way street: An exploration of relationship promotion by professional athletes on Twitter. Communication and Sport, 2(1), 80-99. https://doi.org/2167479512466387

Freeman, P., Rees, T., \& Hardy, L. (2009). An intervention to increase social support and improve performance. Journal of Applied Sport Psychology, 21(2), 186-200. https://doi.org/10.1080/10413200902785829

Fynes-Clinton, J. (2012, August 02). The rise of social media among elite athletes has reached the stage where it is damaging performances says Jane Fynes-Clinton. The Courier Mail. Retrieved from https://goo.gl/x $1 \mathrm{nrSc}$

Gantz, W., \& Trenholm, S. (1979). Why people pass on news: Motivations for diffusion. Journalism Quarterly, 56(2), 365-370. https://doi.org/10.1177 $\underline{107769907905600221}$

Geurin, A. N. (2017). Elite female athletes' perceptions of new media use relating to their careers: A qualitative analysis. Journal of Sport Management, 31(4), 345-359. https://doi.org/10.1123/jsm.2016-0157

Geurin-Eagleman, A. N., \& Burch, L. M. (2016). Communicating via photographs: A gendered analysis of Olympic athletes' visual self-presentation on Instagram. Sport Management Review, 19(2), 133-145. https://doi.org/10.1016/j.smr.2015.03.002

Goodman, F. R., Kashdan, T. B., Mallard, T. T., \& Schumann, M. (2014). A brief mindfulness and yoga intervention with an entire NCAA Division I athletic team: An initial investigation. Psychology of Consciousness: Theory, Research, and Practice, 1(4), 339. http://dx.doi.org/10.1037/cns0000022

Gratton, C., \& Jones, I. (2004). Research Methods for Sports Studies. London: Routledge. Grimm, P. (2010). Social desirability bias. In W. Kamakura (Ed.), Part 2 marketing research, 
Wiley international encyclopedia of marketing (pp. 258 -259). Hoboken, NJ: WileyBlackwell.

Ha, L., \& James, E. L. (1998). Interactivity reexamined: A baseline analysis of early business web sites. Journal of Broadcasting \& Electronic Media, 42(4), 457-474. https://doi.org/10.1080/08838159809364462

Hambrick, M. E., Simmons, J. M., Greenhalgh, G. P., \& Greenwell, T. C. (2010). Understanding professional athletes' use of Twitter: A content analysis of athlete tweets. International Journal of Sport Communication, 3(4), 454-471. https://doi.org $\underline{/ 10.1123 / i j s c .3 .4 .454}$

Hayes Sauder, M., \& Blaszka, M. (2016). 23 Players, 23 Voices: An Examination of the US Women's National Soccer Team on Twitter During the 2015 World Cup. Communication \& Sport, 6(2), 175-202. https://doi.org/10.1177 $\underline{12167479516685579}$

Hull, K. (2014). A hole in one (hundred forty characters): A case study examining PGA Tour golfers' Twitter use during the Masters. International Journal of Sport Communication, 7(2). https://doi.org/10.1123/IJSC.2013-0130

Hutchins, B. (2011). The acceleration of media sport culture: Twitter, telepresence and online messaging. Information, Communication \& Society, 14(2), 237-257. https://doi.org $\underline{/ 10.1080 / 1369118 X .2010 .508534}$

Jones, S. (2012, July 19). London 2012: Athletes share joy and frustration in first Twitter Olympics. The Guardian. Retrieved from https://goo.gl/NTcnnn

Kassing, J. W., \& Sanderson, J. (2010). Fan-athlete interaction and Twitter tweeting through the Giro: A case study. International Journal of Sport Communication, 3(1), 113-128. https://doi.org/10.1123/ijsc.3.1.113

Katz, E., Blumler, J. G., \& Gurevitch, M. (1973). Uses and gratifications research. The Public 
Opinion Quarterly, 37(4), 509-523.

Lee, C. S., \& Ma, L. (2012). News sharing in social media: The effect of gratifications and prior experience. Computers in Human Behavior, 28(2), 331-339. https:// doi.org/10.1016/j.chb.2011.10.002

Lincoln, Y. S., \& Guba, E. G. (1985). Naturalistic inquiry. Beverly Hills, CA: Sage

Morrow, S. L. (2005). Quality and trustworthiness in qualitative research in counseling psychology. Journal of Counseling Psychology, 52(2), 250. https://doi.org/10.1037 $\underline{10022-0167.52 .2 .250}$

Nonnecke, B., Andrews, D., \& Preece, J. (2006). Non-public and public online community participation: Needs, attitudes and behavior. Electronic Commerce Research, 6(1), 720. https://doi.org/10.1007/s10660-006-5985-X

Parmentier, M. A., \& Fischer, E. (2012). How athletes build their brands. International Journal of Sport Management and Marketing, 11(1-2), 106-124. https://doi.org $\underline{\text { 110.1504/IJSMM.2012.045491 }}$

Pegoraro, A. (2010). Look who's talking —athletes on Twitter: A case study. International Journal of Sport Communication, 3(4), 501-514. https://doi.org/10.1123/ijsc.3.4.501

Quan-Haase, A., \& Young, A. L. (2010). Uses and gratifications of social media: A comparison of Facebook and instant messaging. Bulletin of Science, Technology \& Society, 30(5), 350-361. https://doi.org/10.1177/0270467610380009

Raacke, J., \& Bonds-Raacke, J. (2008). Myspace and Facebook: Applying the uses and gratifications theory to exploring friend-networking sites. Cyber Psychology \& Behaviour, 11(2), 169-174. https://doi.org/10.1089/cpb.2007.0056

Reja, U., Manfreda, K. L., Hlebec, V., \& Vehovar, V. (2003). Open-ended vs. close-ended questions in web questionnaires. Developments in applied statistics, 19(1), 160-117.

Ritzer, G., \& Jurgenson, N. (2010). Production, consumption, prosumption. The nature of 
capitalism in the age of the digital 'prosumer'. Journal of Consumer Culture, 10(1), 13-36. https://doi.org.10.1177/1469540509354673

Rowley, T. (2012, July 31). London 2012 Olympics: the first Twitter Games opens debate of athletes using social media. The Telegraph. Retrieved from https://goo.gl/g1msUY

Ruggiero, T. E. (2000). Uses and gratifications theory in the 21 st century. Mass Communication \& Society, 3(1), 3-37. https://doi.org/10.1207 $\underline{\text { S } 15327825 \mathrm{MCS} 0301 \quad 02}$

Sanderson, J. (2013). Social media and sport communication: Abundant theoretical opportunities. In P. M Pedersen (Ed.). Routledge Handbook of Sport Communication. London, UK: Routledge.

Sanderson, J., Browning, B., \& Schmittel, A. (2015). Education on the digital terrain: A case study exploring college athletes' perceptions of social-media training. International Journal of Sport Communication, 8(1), 103-124. https://doi.org/10.1123/IJSC.2014$\underline{0063}$

Sanderson, J., \& Truax, C. (2014). “I hate you man!”: Exploring maladaptive parasocial interaction expressions to college athletes via Twitter. Journal of Issues in Intercollegiate Athletics, 7, 333-351.

Siggelkow, N. (2007). Persuasion with case studies. The Academy of Management Journal Archive, 50(1), 20-24. http://www.jstor.org/stable/20159838

Spall, S. (1998). Peer debriefing in qualitative research: Emerging operational models. Qualitative Inquiry, 4(2), 280-292. https://doi.org/10.1177 $\underline{107780049800400208}$

Sriwilai, K., \& Charoensukmongkol, P. (2016). Face it, don't Facebook it: impacts of social media addiction on mindfulness, coping strategies and the consequence on emotional exhaustion. Stress and Health, 32(4), 427-434. https://doi.org/10.1002/smi.2637 
1 Suri, H. (2011). Purposeful sampling in qualitative research synthesis. Qualitative research journal, 11(2), 63-75. https://doi.org/10.3316/QRJ1102063

3 Tracy, S. J. (2013). Qualitative Research Methods. UK: Wiley-Blackwell.

4 Wimmer, R. D., \& Dominick, J. R. (2003). Mass Media Research: An Introduction. Belmont, 5 CA: Wadsworth. 
Appendix A: Tables

Table 1

Respondent profile $(N=53)$

\begin{tabular}{lrr}
\hline \multicolumn{1}{c}{ Variable } & $\boldsymbol{n}$ & $\mathbf{( \% )}$ \\
\hline Gender & 31 & 58.49 \\
Female & 21 & 39.62 \\
Male & 1 & 1.89 \\
Prefer not to disclose & 32 & 60.37 \\
& 17 & 32.08 \\
15-24 & 4 & 7.55 \\
25-34 & & \\
35-44 & 1 & 1.89 \\
Event & 1 & 1.89 \\
Artistic Gymnastics World Championships & 5 & 9.43 \\
Archery World Championships & 10 & 18.87 \\
Asian Indoor Martial Arts Games & 3 & 5.66 \\
Athletics World Championships & 2 & 3.77 \\
Aquatic (FINA) World Championships & 1 & 1.89 \\
Beach Volleyball World Championships & 2 & 3.77 \\
Canoe Sprint World Championships & 4 & 7.55 \\
Hockey Oceania Cup & 1 & 1.89 \\
Mountain Bike World Championships & 2 & 3.77 \\
Oceania Continental Climbing Championships & 2 & 3.77 \\
Rhythmic Gymnastics World Championships & 5 & 9.43 \\
Road Cycling World Championships & 1 & 1.89 \\
Rowing World Championships & 1 & 1.89 \\
Short Track Speed Skating World Cup & 2 & 3.77 \\
Squash World Doubles Championships & 4 & 7.55 \\
Trampoline Gymnastics World Championships & 3 & 5.66 \\
Triathlon Grand Final & 2 & 3.77 \\
Winter Games (New Zealand) & 1.89 \\
Women's Rugby World Cup & & \\
World Roller Games & & \\
\hline & & \\
\hline
\end{tabular}


Table 2

Study One Themes, Operational Definitions, and Example Quote

\begin{tabular}{|c|c|c|}
\hline Theme & Operational Definition & Example Quote \\
\hline Communication with Supporters & $\begin{array}{l}\text { Social media providing an avenue for } \\
\text { athletes to keep in contact with key support } \\
\text { networks }\end{array}$ & $\begin{array}{l}\text { "Mainly for communication with family and } \\
\text { friends as normal phone access is not } \\
\text { normally available. It's a simple way of } \\
\text { communicating your experience for anyone } \\
\text { that might be interested and to pass on } \\
\text { important info on the competition itself." }\end{array}$ \\
\hline Promotion & $\begin{array}{l}\text { An avenue for athletes to increase their } \\
\text { personal profile and the profile of their } \\
\text { sponsors during the event }\end{array}$ & $\begin{array}{l}\text { "I am required to promote, however, it is } \\
\text { not specified to any particular amount/time. } \\
\text { I had planned to post every couple of days } \\
\text { around the event." }\end{array}$ \\
\hline Information Gathering and Sharing & $\begin{array}{l}\text { The sharing and gathering of information } \\
\text { related to the event such as competition } \\
\text { times and information on competitors }\end{array}$ & $\begin{array}{l}\text { "Researching competitors in my division. } \\
\text { To distract myself from the games' } \\
\text { atmosphere. Finding the schedule for } \\
\text { competition and monitoring for changes to } \\
\text { schedule. Checking medal count and how } \\
\text { other sports within the team are } \\
\text { performing." }\end{array}$ \\
\hline Connectedness & $\begin{array}{l}\text { Athletes striving to feel connected to the } \\
\text { outside world, support networks, and the } \\
\text { event }\end{array}$ & $\begin{array}{l}\text { "Together, they mostly made me feel } \\
\text { connected to the world, up to date on the } \\
\text { championships - other athlete's form, } \\
\text { teammate's results etc. Not a lot changed } \\
\text { from normal life use of social media or the } \\
\text { consequences of it." }\end{array}$ \\
\hline Positive Reinforcement & $\begin{array}{l}\text { Athletes receiving satisfaction through } \\
\text { supportive messages from followers and } \\
\text { support networks (e.g., family and friends) }\end{array}$ & $\begin{array}{l}\text { "It [using social media] allowed me to } \\
\text { receive numerous kind messages of support } \\
\text { which improved my confidence." }\end{array}$ \\
\hline
\end{tabular}


Relaxation and Escape

Anxiousness

Balancing social media use
Athletes seeking an escape from their sport or the pressures associated with competing

Athletes feeling uneasy through the content they were exposed to and posting on their social media pages

Athletes finding it difficult to balance an appropriate level of social media use
"It only benefits me to relax myself and take my mind off my sport when I am not needed to focus on it. I don't like to always be switched onto athletics while at championships because it mentally fatigues me."

"It made me feel a little anxious in the lead up to competition as I didn't want to know or see other competitor's results which would increase the pressure on my performances."

"Keep my life as normal as possible during competition. Just because I was at an event I didn't want that to change my other behaviours." 
Table 3

Respondent Breakdown $(N=53)$

\begin{tabular}{|c|c|c|c|c|c|}
\hline \multicolumn{3}{|c|}{ Female } & \multicolumn{3}{|c|}{ Male } \\
\hline Number & Sport & Age & Number & Sport & Age \\
\hline 1 & Synchronised Swimming & 22 & 7 & Cross-country skiing & 26 \\
\hline 2 & Synchronised Swimming & 19 & 13 & Wrestling & 24 \\
\hline 3 & Synchronised Swimming & 21 & 15 & Weightlifting & 23 \\
\hline 4 & Rhythmic Gymnastics & 25 & 17 & Weightlifting & 22 \\
\hline 5 & Squash & 25 & 23 & Mountain Bike & 20 \\
\hline 6 & Cross-country skiing & 21 & 25 & Triathlon & 19 \\
\hline 8 & Roller Derby & 27 & 27 & Triathlon & 20 \\
\hline 9 & Cross-country skiing & 30 & 28 & Athletics & 24 \\
\hline 10 & Rugby & 38 & 29 & Athletics & 25 \\
\hline 12 & Beach Volleyball & 21 & 30 & Triathlon & 22 \\
\hline 14 & Taekwondo & 19 & 31 & Athletics & 23 \\
\hline 16 & Wrestling & 23 & 32 & Athletics & 20 \\
\hline 18 & Rugby & 39 & 33 & Triathlon & 17 \\
\hline 19 & Mountain Bike & 20 & 34 & Athletics & 20 \\
\hline 20 & Athletics & 25 & 37 & Speed Skating & 17 \\
\hline 21 & Mountain Bike & 21 & 38 & Road Cycling & 26 \\
\hline 22 & Athletics & 35 & 44 & Beach Volleyball & 29 \\
\hline 24 & Road Cycling & 31 & 46 & Rowing & 25 \\
\hline 26 & Athletics & 30 & 48 & Rowing & 25 \\
\hline 35 & Canoe Sprint & 20 & 49 & Rowing & 24 \\
\hline 36 & Athletics & 24 & 52 & Trampoline Gymnastics & 20 \\
\hline 39 & Artistic Gymnastics & 16 & & & \\
\hline 40 & Mountain Bike & 33 & & & \\
\hline 41 & Hockey & 31 & & & \\
\hline 42 & Hockey & 20 & & & \\
\hline 43 & Archery & 43 & & & \\
\hline 45 & Athletics & 20 & & & \\
\hline 47 & Rowing & 30 & & & \\
\hline 50 & Rowing & 22 & & & \\
\hline 51 & Climbing & 33 & & & \\
\hline 53 & Trampoline Gymnastics & 18 & & & \\
\hline
\end{tabular}

Note. Respondent 11 did not disclose a gender, however, was a 17-year-old rhythmic gymnastics athlete. 
Table 4

Time Spent on Social Media

\begin{tabular}{|c|c|c|c|c|c|c|}
\hline & $\begin{array}{c}\text { Several } \\
\text { times a } \\
\text { day }\end{array}$ & Daily & $\begin{array}{c}\text { Several } \\
\text { times a } \\
\text { week }\end{array}$ & $\begin{array}{c}\text { Once a } \\
\text { week }\end{array}$ & $\begin{array}{l}\text { Once a } \\
\text { month }\end{array}$ & Never \\
\hline \multicolumn{7}{|c|}{ Everyday Use } \\
\hline Twitter & $7.55 \%$ & $13.21 \%$ & $5.66 \%$ & $9.43 \%$ & $9.43 \%$ & $54.72 \%$ \\
\hline Facebook & $62.26 \%$ & $24.53 \%$ & $7.55 \%$ & $3.77 \%$ & $0.00 \%$ & $1.89 \%$ \\
\hline Instagram & $73.58 \%$ & $16.98 \%$ & $3.77 \%$ & $1.89 \%$ & $0.00 \%$ & $3.77 \%$ \\
\hline Snapchat & $43.40 \%$ & $16.98 \%$ & $5.66 \%$ & $5.66 \%$ & $0.00 \%$ & $28.30 \%$ \\
\hline Others & $5.66 \%$ & $3.77 \%$ & $5.66 \%$ & $3.77 \%$ & $0.00 \%$ & $81.13 \%$ \\
\hline \multicolumn{7}{|c|}{ Intended Event Use } \\
\hline Twitter & $3.77 \%$ & $16.98 \%$ & $3.77 \%$ & $9.43 \%$ & $3.77 \%$ & $62.26 \%$ \\
\hline Facebook & $41.51 \%$ & $37.74 \%$ & $9.43 \%$ & $5.66 \%$ & $0.00 \%$ & $5.66 \%$ \\
\hline Instagram & $49.06 \%$ & $32.08 \%$ & $9.43 \%$ & $5.66 \%$ & $0.00 \%$ & $3.77 \%$ \\
\hline Snapchat & $28.30 \%$ & $26.42 \%$ & $5.66 \%$ & $3.77 \%$ & $0.00 \%$ & $35.85 \%$ \\
\hline Others & $3.77 \%$ & $9.43 \%$ & $1.89 \%$ & $5.66 \%$ & $0.00 \%$ & $79.25 \%$ \\
\hline \multicolumn{7}{|c|}{ Actual Event Use } \\
\hline Twitter & $7.55 \%$ & $13.21 \%$ & $7.55 \%$ & $1.89 \%$ & $0.00 \%$ & $69.81 \%$ \\
\hline Facebook & $54.72 \%$ & $24.53 \%$ & $11.32 \%$ & $3.77 \%$ & $0.00 \%$ & $5.66 \%$ \\
\hline Instagram & $64.15 \%$ & $26.42 \%$ & $5.66 \%$ & $0.00 \%$ & $0.00 \%$ & $3.77 \%$ \\
\hline Snapchat & $35.85 \%$ & $24.53 \%$ & $7.55 \%$ & $3.77 \%$ & $0.00 \%$ & $28.30 \%$ \\
\hline Others & $7.55 \%$ & $7.55 \%$ & $5.66 \%$ & $3.77 \%$ & $0.00 \%$ & $75.47 \%$ \\
\hline
\end{tabular}




\section{Appendix B: Open-Ended Questionnaire}

\section{Section 1: Demographics}

Q1: Which of the following major sport events have you recently competing in?

$\square 2017$ Artistic Gymnastics World Championships

2017 Asian Indoor and Martial Arts Games

2017 Asian Men's Volleyball Championships

2017 Asian Women's Volleyball Championships

2017 Audi Quattro Winter Games (NZ)

2017 Badminton BWF World Championships

2017 Beach Volleyball World Championships

2017 Commonwealth and Oceania Weightlifting Championships

2017 Fast 5 Netball World Series

2017 FINA Diving Grand Prix (Gold Coast)

2017 FINA World Championships

2017 FINA World Junior Swimming Championships

2017 IAAF World Athletics Championships

2017 ICF Sprint Canoe World Championships

2017 ICF Canoe Slalom World Championships

2017 ITU World Triathlon Grand Final

2017 Ocean Cup (Hockey)

2017 Oktoberfest 7s

2017 Rhythmic Gymnastics World Championships

2017 Short Track Speed Skating World Cup

$\square 2017$ Trampoline Gymnastics World Championships

2017 Tournament of Nations

2017 U23s Rowing World Championships

2017 UCI MTB World Championships

2017 Women's Rugby World Cup

2017 World Rowing Championships

2017 World Archery Championships

2017 World Roller Games

2017 WSF World Doubles Squash Championships

$\square$ None of the above

$\square$ Other (please provide)

Q2: Are you:

$\square$ Male

$\square$ Female

$\square$ Prefer not to disclose

Q3: Please record your age

\section{Section 2: Social Media Platforms \& Access}

Q4: Do you have a social media account/s?

$\square$ Yes

$\square$ No

Q5: Do you intend to access your social media accounts during your selected major sports event?

$\square$ Yes

$\square$ No

Q6: Please select which of the following platforms you planned to access during your 
selected major sports event: (You may select more than one).

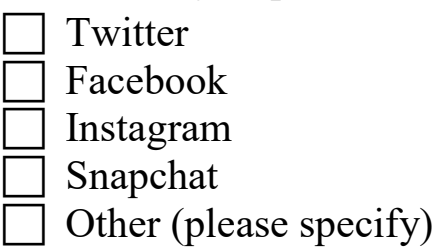

Q7: How often do you access each of the following social media accounts for everyday use? Please provide an answer for every platform. (If you do not use a certain platform, please select never).

\begin{tabular}{|l|l|l|l|l|l|l|}
\hline & $\begin{array}{c}\text { Several } \\
\text { times daily }\end{array}$ & Daily & $\begin{array}{c}\text { Several } \\
\text { times a } \\
\text { week }\end{array}$ & $\begin{array}{c}\text { Once a } \\
\text { week }\end{array}$ & $\begin{array}{c}\text { Once a } \\
\text { month }\end{array}$ & Never \\
\hline Twitter & & & & & & \\
\hline Facebook & & & & & & \\
\hline Instagram & & & & & & \\
\hline Snapchat & & & & & & \\
\hline Others & & & & & & \\
\hline
\end{tabular}

Q8: How often didyou plan to access each of the following social media accounts during your selected major sports event? Please provide an answer for every platform. (If you do not use a certain platform, please select never).

\begin{tabular}{|l|l|l|l|l|l|l|}
\hline & $\begin{array}{c}\text { Several } \\
\text { times daily }\end{array}$ & Daily & $\begin{array}{c}\text { Several } \\
\text { times a } \\
\text { week }\end{array}$ & $\begin{array}{c}\text { Once a } \\
\text { week }\end{array}$ & $\begin{array}{c}\text { Once a } \\
\text { month }\end{array}$ & Never \\
\hline Twitter & & & & & & \\
\hline Facebook & & & & & & \\
\hline Instagram & & & & & & \\
\hline Snapchat & & & & & & \\
\hline Others & & & & & & \\
\hline
\end{tabular}

\section{Section 3: Purposes for Social Media Use}

Q9: For what purposes will you use social media during your selected major sports event? Please describe.

Q10: Are you required to promote sponsors during your selected major sports event via your social media accounts? If so, how did you plan to do this?

Q11: If you could not use social media during your selected major sports events, how would it impact you? Please describe in as much detail as possible.

Q12: How does using social media during a major sports event benefit you? Please describe in as much detail as possible.

Q13: What satisfaction did you intend to gain from using social media during your selected major sport event?

Q14: How often did you access each of the following social media accounts during your selected major sports event? Please provide an answer for every platform. (If you do not use a certain platform, please select never).

\begin{tabular}{|c|c|c|c|c|c|c|}
\hline & $\begin{array}{c}\text { Several } \\
\text { times daily }\end{array}$ & Daily & $\begin{array}{c}\text { Several } \\
\text { times a }\end{array}$ & $\begin{array}{c}\text { Once a } \\
\text { week }\end{array}$ & $\begin{array}{c}\text { Once a } \\
\text { month }\end{array}$ & Never \\
\hline
\end{tabular}




\begin{tabular}{|l|l|l|l|l|l|l|}
\hline & & & week & & & \\
\hline Twitter & & & & & & \\
\hline Facebook & & & & & & \\
\hline Instagram & & & & & & \\
\hline Snapchat & & & & & & \\
\hline Others & & & & & \\
\hline
\end{tabular}

Q15: For what purposes did you use social media during your selected major sports event?

Please describe.

Q16: How did using social media during your selected major sports event benefit you? Please describe in as much detail as possible.

Q17: How were your goals for social media use at your selected major sports event achieved? Please describe in as much detail as possible.

Q18: How did using social media at your selected major sports event make you feel (e.g., relaced, happy, anxious). Please describe in as much detail as possible.

Q19: Would you change the way you use social media for future major sport events? Please describe in as much detail as possible. 